\title{
Vaivenes jurisprudenciales: Fumigaciones en la provincia de Entre Ríos
}

\author{
Jurisprudential fluctuations: Fumigations in the \\ province of Entre Rios
}

\section{Vaivéns jurisdicionais: Fumigações na Província de Entre Ríos \\ Oscillations jurisprudentielles: fumigations dans la province d'Entre Ríos \\ 法学的风风雨雨:恩特雷里奥斯省的熏蒸}

\author{
Juan Ignacio Moreno ${ }^{1}$ \\ Universidad Nacional de La Plata - Argentina
}

Revista Derechos en Acción ISSN 2525-1678/ e-ISSN 2525-1686

Año 5/No 16 Invierno 2020 (21 junio a 20 septiembre), 419-439

DOl: https://doi.org/10.24215/25251678e429

Recibido: 16/05/2020

Aprobado: 01/08/2020

Resumen: En la provincia de Entre Ríos se desarrolla un modelo de agricultura industrial que trajo como consecuencias una afectación sobre la salud de niños y docentes de escuelas rurales. Ante un planteo ecológico resulta trascendental que el mismo sea social ya que incide sobre todas las personas. Mediante un análisis de la legislación entrerriana y la causa judicial "Foro Ecologista contra Superior Gobierno de la Provincia de Entre Ríos" (2018-2020) se apreciará la postura mercantilista del agronegocio y el reclamo de los pueblos fumigados que buscan vivir dignamente.

Abogado (UNLP). Maestrando en Derechos Humanos (UNLP). Colaborador en la materia Derecho Agrario Cátedra 3 de la Facultad de Ciencias Jurídicas y Sociales (UNLP). Investigador (FCJyS-UNLP). Contacto: ignacio_moreno@live.com.ar (ORCID: https://orcid. org/0000-0002-9516-3456). 
Palabras claves: fumigación, agronegocio, foro ecologista, Entre Ríos.

Abstract: In the Entre Ríos province, an industrial agriculture model is being developed that has had consequences for the health of children and teachers in rural schools. Faced with an ecological approach, it is transcendental that it is social because it affects all people. Through an analysis of Entre Ríos legislation and the judicial case "Ecological Forum against Superior Government of the Province of Entre Ríos" (2018-2020), the mercantile stance of agribusiness and the claim of fumigated peoples seeking to live with dignity will be appreciated.

Keywords: fumigation, agribusiness, ecological forum, Entre Ríos.

Resumo: Na província de Entre Ríos desenvolve-se um modelo agrícola industrial que trouxeum como consequências uma afetação para a saúde das crianças e professores das escolas rurais. Frente numa proposta ecológica é importante que seja social, pois afecta todas as pessoas. Através da análise da legislação de Entre Ríos e do processo judicial "Foro Ecologista contra Superior Gobierno de la Provincia de Entre Ríos" (2018-2020) mostrará a posição mercantilista do agronegócio e as exigências dos povos fumigados que procuram viver com dignidade.

Palavras-chave: Fumigação, agronegócio, fórum ambiental, Entre Ríos.

Résumé: Dans la province d'Entre Ríos, un modèle d'agriculture industrielle est en cours d'élaboration qui a affecté la santé des enfants et des enseignants des écoles rurales. Face à une démarche écologique, il est transcendantal qu'elle soit sociale puisqu'elle touche tout le monde. Grâce à une analyse de la législation d'Entre Ríos et de l'affaire judiciaire "Forum écologiste contre le gouvernement supérieur de la province d'Entre Ríos (2018-2020)". La position mercantile de l'agroindustrie et la revendication des peuples fumigés qui cherchent à vivre dignement seront appréciées.

Mot-clés: fumigation, agro-industrie, forum environnemental, Entre Ríos.

摘要：在恩特雷里奥斯省，正在开发一种模式农业，这种模式已经 影响了农村学校儿童和教师的健康. 面对生态方法它是社会的, 因 为它影响到所有人, 这是超验的. 通过对恩特雷里奥斯的立法和司 法案件“反对恩特里里奥斯省上级政府的生态学家论坛(2018-2020 
年)进行分析将赞赏农业综合企业的商业立场以及寻求有尊严生活 的熏蒸人民的主张

关键词: 熏蒸, 农业综合企业, 环境论坛, Entre Ríos (河流之间)

\section{Introducción}

En el presente trabajo se desarrollarán las consecuencias de las fumigaciones terrestres y aéreas en la provincia de Entre Ríos desde su legislación y jurisprudencia.

Inicialmente es procedente comprender el contexto de la agricultura argentina para llegar a los reclamos judiciales respecto a las consecuencias, provocadas por las fumigaciones, sobre la salud humana y al ambiente.

La extensión territorial y fertilidad de los suelos rurales argentinos conllevan un necesario análisis sobre las prácticas agrícolas. En cuanto a las condiciones agroecológicas, como tecnología en la faz productiva, la Argentina es uno de los cuatro lugares más aptos para ampliar su oferta en la producción de alimentos (Agroindustria, 2017, pág.1). Pensar una actividad agrícola sustentada en insumos químicos resulta contraproducente hacia los recursos naturales como a su vez en el alimento final. En este sentido la necesidad por obtener divisas, a través de las agroexportaciones, genera un ámbito propicio para la agricultura industrial basada en un paquete tecnológico.

Dentro de este contexto es dable analizar las palabras esbozadas por el vicepresidente de la Federación Agraria ante la resolución del Superior Tribunal de Justicia de Entre Ríos sobre áreas de fumigación: "Es mucho más fácil reubicar las escuelas que cambiar el modo de producción"2.

En el marco de estas palabras se entrecruzan distintos intereses y consecuencias del modelo agroexportador. Una de las

\footnotetext{
2 Nota del medio Página 12 del día 21/05/2019 bajo el título “Entre Ríos: insólita defensa de los agrotóxicos" https://www.pagina12.com.ar/195153-entre-rios-insolita-defensa-delos-agrotoxicos
} 
consecuencias es el desarraigo de las zonas rurales, es decir, un campo sin gente. Tras datos arrojados por el último Censo Nacional Agropecuario, realizado por el INDEC, se ha reflejado una merma en la población rural donde durante el período 2002-2018 se perdió el 25,5\% de explotaciones agropecuarias. Esto infiere que el modelo del agronegocio ha avanzado sobre las pequeñas explotaciones agropecuarias implicando que los productores se conviertan en arrendadores de las tierras que hasta hace poco trabajaban.

Mediante el censo se exhibió una concentración en las explotaciones agropecuarias donde se visibiliza un campo empresarial que excluye a los verdaderos agricultores que trabajan la tierra. De esta manera se genera una ampliación entre la brecha del campo empresarial respecto a los pequeños $\mathrm{y}$ medianos productores que integran la agricultura familiar.

Estos datos visibilizaron la consolidación de latifundios a lo largo de toda la Argentina donde grandes extensiones de tierras quedan distribuidas entre pocos propietarios. Este modelo de campo, con una economía a gran escala, ha incorporado una política de expulsión de los pequeños agricultores en su territorio. Es fiel al pensamiento del agronegocio esta mirada de cerrar escuelas rurales para continuar con una agricultura intensiva.

Esta situación actual se ha trazado a través de un sistema productivo de agricultura industrial y pools de siembra para brindar respuestas inmediatas a las necesidades del país.

Este sistema de producción ocasionó un cambio de paradigma en la agricultura argentina. Se incrementó la aplicación de insumos químicos como agroquímicos, fertilizantes, semillas genéticamente modificadas que brindaron efectividad. Esto ha generado una pérdida de autonomía como de identidad para los productores que pasan a depender de un pequeño grupo de empresas proveedoras de semillas (Giarraca y Teubal, 2006, pág.79). Además, dicha efectividad económica encubre la contaminación sobre los suelos y el agua derivando en una vulneración de la salud y la vida humana. 
A partir de este sistema de agricultura industrial se orientó la producción de alimentos hacia ciertos cultivos con mayor demanda en el mercado internacional. Uno de los casos más notables se ha suscitado con la soja. Las oleaginosas, en nuestro país, comprenden sobre la superficie plantada unos 14 millones de hectáreas ${ }^{3}$ superando a las cerealeras que comprenden unos 11 millones de hectáreas plantadas. Dentro de las oleaginosas la soja representa el 88,5\% ${ }^{4}$ mientras que el girasol ocupa 7,9\% sobre superficie implantada. Estos números se reflejan en el comercio internacional de la Argentina donde la exportación de la soja y sus derivados (como porotos, harina y aceite de soja) han acumulado en el año 201916 mil millones de dólares 5 marcando un incremento respecto al año 2018 que recaudó unos 15 mil millones de dólares ${ }^{6}$.

En el aspecto internacional la Argentina se encuentra beneficiada ante la oportunidad de una ganancia constante sobre el monocultivo de la soja. Dicho cultivo es producido, en mayor medida, por la Argentina, Brasil y Estados Unidos. La Argentina solamente consume el $10 \%$ de la producción de soja y el resto se exporta a diferencia de Brasil o Estados Unidos que consumen la mitad en la producción de esta oleaginosa (Burgos, 2016, pág.33). El principal destinatario de la soja es China, un país que diversifica su producción en aquellas actividades que requieren de una mayor mano de obra garantizando un arraigo

3 Datos del INDEC del Censo Nacional Agropecuario, períodos 1 de julio 2017 al 30 de junio 2018, sobre Superficie implantada por tipo de cultivo en hectáreas. Total de país. https:// www.indec.gob.ar/indec/web/Institucional-Indec-Multimedia-1

4 Datos del INDEC del Censo Nacional Agropecuario, períodos 1 de julio 2017 al 30 de junio 2018, sobre Agricultura superficie implantada de oleaginosas en primera y segunda ocupación. Total de país. https://www.indec.gob.ar/indec/web/Institucional-Indec-Multimedia-1

5 Informes Técnicos vol.4 $n^{0}$ 13, Comercio Exterior vol.4 $n^{0}$ 1, Cifras Estimadas de 2019. Publicado en enero 2020. https://www.indec.gob.ar/uploads/informesdeprensa/ ica_01_20B13D104EBD.pdf

6 Datos del INDEC en Informes Técnicos vol. $3 n^{0} 38$, Comercio Exterior vol. $3 n^{0} 4$ sobre "Complejos Exportadores" (2018) publicado en marzo de 2019. https://sitioanterior.indec. gob.ar/uploads/informesdeprensa/complejos_03_19.pdf 
rural de los agricultores. A diferencia de la soja que requiere una menor cantidad de mano de obra en virtud de lo cual China sustenta su consumo de soja mediante importaciones.

En la provincia de Entre Ríos se desarrolla este modelo de agricultura industrial con el cultivo de la soja. La provincia del litoral argentino produce unos 3,9 millones de tonelada de soja para la provincia ${ }^{7}$ sobre una superficie de 2 millones de hectáreas de su territorio. Convirtiéndose en una de las provincias que mayor aporte realiza para la exportación de este cultivo. Por ende, se genera una dependencia económica y productiva sobre un monocultivo que queda supeditado a los intereses de China.

El modelo agroexportador trae aparejado problemáticas sociales y ambientales que se ven sesgadas por el ingreso inmediato de divisas internacionales ante las necesidades económicas del país. Además, comprende una nueva forma de concebir a la agricultura donde la importancia productiva ya no recae en proveer alimentos sino en producir mercancías de acuerdo con la demanda internacional (Gudynas, 2010, pág. 41).

A continuación, se tratará el marco regulatorio sobre las fumigaciones aéreas y terrestres y como ha sido modificada en un beneficio empresarial ignorando las consecuencias de esta agricultura industrial.

\section{Legislación provincial}

Para dimensionar las consecuencias de los agroquímicos es primordial abordar su marco legal. En este punto se analizará la legislación más destacada sobre las distintas formas de aplicación (terrestre y aérea) de los agroquímicos y como la exigua limitación termina afectando derechos humanos.

Una de las primeras normativas para mencionar consiste en la Ley de Plaguicidas n 6599 que tiene por objeto el expendio, aplicación, transporte y almacenamiento de plaguicidas.

7 Datos de la página del gobierno de Entre Ríos. Disponibles en: https://www.entrerios.gov. $\mathrm{ar} /$ portal $/$ index.php?codigo $=32 \&$ codsubmenu $=72 \&$ menu $=$ menu\&modulo $=$ 
La Subsecretaría de Asuntos Agrarios, en particular la Dirección General de Desarrollo Agrícola y Recursos Naturales, es el órgano de aplicación de la ley quien se encarga de llevar un Registro de Expendedores y Aplicadores (al igual que en la legislación de la Provincia de Buenos Aires los aplicadores deben contar con el asesoramiento de un Ingeniero Agrónomo).

El Registro de Expendedores y Aplicadores cuenta con una inscripción online en la página del gobierno provincial y requiere previamente estar registrado en el Sistema de Gestión de Recetas Agronómicas Online (en este sistema de recetas agronómicas se determina el lote para su utilización y los lotes lindantes para tener una precisión geográfica de la actividad). Mediante este sistema la Dirección de Agricultura puede constatar la documentación requerida para la inscripción y evitar errores en declaraciones juradas como ante la falta de credenciales.

En base a esta normativa, la Dirección General de Desarrollo Agrícola se encargará de publicar anualmente los biocidas inscriptos con su grado de toxicidad.

Respecto al almacenamiento de los agroquímicos, se determina que su ubicación geográfica debe encontrarse alejada de concentraciones de personas. Sobre el transporte, de estos insumos químicos, se exige un traslado que evite el riesgo de la contaminación. También se establecen multas ante la violación de esta normativa.

Cabe destacar la importancia de su art. 8 frente a reglamentaciones que sucedieron a esta ley. Dicho artículo establece que los aplicadores, por vía aérea o terrestre, deberán tomar precauciones para evitar ocasionar daños a terceros.

Para aplicar esta ley, la provincia cuenta con una Nómina de Empresas Expendedoras y Aplicadoras de estos agroquímicos. Esta nómina detalla el tipo de equipo utilizado en las fumigaciones y datos relevantes como el nombre de la empresa, su CUIT, localidad y el asesor a cargo de este ejercicio acompañado de una columna que exhibe si se encuentra habilitado. 
Un último aspecto para tener en consideración, especialmente en la lectura de los fallos, es que el decreto reglamentario 279/03, de la ley de plaguicidas, en su art.12 prohíbe la fumigación aérea a unos 3000 metros del ejido urbano.

\section{Un retroceso legal}

El día 2 de enero del 2019 se puso en vigencia el Decreto $4407 / 18$, en el marco de la ley de plaguicidas $n^{\circ} 6599$ y Decreto Reglamentario $\mathrm{n}^{\circ} 279 / 03$, con el fin de regular los límites a la aplicación de agroquímicos en el territorio de la provincia de Entre Ríos. En dicha normativa se estableció la prohibición de fumigaciones terrestres a tan solo 100 metros de escuelas rurales. Para las aplicaciones aéreas se estableció un límite de 500 metros de los establecimientos educativos. Ambas disposiciones resultan ultrajantes hacia los principios precautorio y preventivo de la ley 25675 considerando los efectos de la deriva al momento de fumigarse ${ }^{8}$.

La irresponsabilidad de este decreto invisibiliza el efecto silencioso que se materializa a través en la contaminación de los agroquímicos. Por eso es preciso comprender el efecto de la deriva en las fumigaciones aéreas. La deriva es entendida como aquel desplazamiento del contenido químico de los agroquímicos fuera del punto establecido por masas de aire o falta de adherencia (Tomasoni, 2013, pág.1). Por ende, las consecuencias de estas partículas pueden provocar daños sobre las cuencas de agua, la biodiversidad y la vida de los pobladores. Por dicho motivo las normativas establecen que las fumigaciones se realicen bajo ciertas condiciones climáticas para evitar los vientos, la humedad y determinadas temperaturas que inciden en los efectos de la deriva.

\footnotetext{
8 Las fumigaciones pueden presentar sus consecuencias a través del tiempo. El caso más explícito es el efecto de la deriva en las fumigaciones aéreas que generan desplazamiento del contenido de los agroquímicos fuera del aérea a fumigar y que trae como consecuencia su vuelco sobre cuencas de agua y viviendas.
} 
A su vez, es preciso apreciar los efectos fisicoquímicos en la deriva del producto aplicado. En el trabajo "No bay fumigación controlable, generación de derivas de plaguicidas" del Ing. Químico Marcos Tomasoni, se explica las consecuencias de estos efectos como el tamaño de la gota donde a menor diámetro la gota permanecerá más tiempo en el aire con mayor superficie de evaporación mientras que una gota de mayor diámetro genera una caída más rápida con mayor rebote sobre la hoja generando un escurrimiento. Otro efecto que se menciona en este trabajo es la evaporación de la gota, es decir, cuando se convierte a la fase gaseosa antes de llegar al punto exacto de aplicación ocasionando una contaminación atmosférica. Por último, se detalla los efectos tecnológicos respecto a las técnicas de aplicación como la calibración de equipos aplicadores, alturas y presión de aspersión y velocidad de la máquina.

Volviendo al marco legislativo, el 1 de agosto de 2019 se derogó el decreto 4407/18 tras reclamos judiciales que luego se abordarán en el siguiente capítulo. En cuanto al nuevo decreto $2239^{9}$, que reglamentaba la ley de plaguicidas provincial, dispuso una zona de exclusión de 100 metros para aplicaciones terrestres y 500 metros para fumigaciones aéreas sobre a escuelas rurales. También se determinó un área de restricción donde se prohibía la aplicación terrestre de agroquímicos I y II en el radio de 500 metros, aunque podrían realizarse fumigaciones con los agroquímicos de clase III y IV (este último incluye al glifosato). Y se prohibía la fumigación aérea en una zona de restricción de 3000 metros desde el límite de 500 metros para los agroquímicos con toxicidad de I y II pero si podría fumigarse con los de clase III y IV.

Además, se dispuso la aplicación de Buenas Prácticas Fitosanitarias y la Guía de Uso Responsable de Agroquímicos fuera del horario escolar y fines de semana. Realmente estás buenas prácticas carecen de efectividad ya que fijan límites irrisorios para

9 Decreto 2239 disponible en: https://www.entrerios.gov.ar/boletin/calendario/Boletin/ 2019/Agosto/05-08-19.pdf 
la aplicación de agroquímicos exponiendo, en este caso, a niños y docentes a una afectación sobre su salud. Quedó suficientemente detallado las consecuencias de las fumigaciones como el efecto de la deriva y se le adhiere la complejidad del glifosato sabiendo de su impacto negativo sobre la salud humana.

\section{Marchas y contramarchas judiciales}

Las fumigaciones acaecidas en la provincia de Entre Ríos atravesaron distintas resoluciones del poder judicial provincial. Se presentaron reclamos judiciales ante la vulneración de derechos humanos y en tan solo dos años el Superior Tribunal de Entre Ríos (STJ) se expidió en cinco ocasiones.

A continuación, se analizarán las distintas posturas que sostuvo el Superior Tribunal de Entre Ríos en la causa del "Foro Ecologista de Paraná contra el Superior Gobierno de la Provincia de Entre Ríos".

1) "FORO ECOLOGISTA DE PARANA y OTRA C/ SUPERIOR GOBIERNO DE LA PROVINCIA DE ENTRE RIOS y OTRO S/ ACCION DE AMPARO" (Causa N ${ }^{\circ} 23709$ )

El día 29 de octubre de 2018 la sala de Procedimientos Constitucionales y Penales del Superior Tribunal de Justicia de Entre Ríos, se expidió ante la causa $n^{\circ} 23709$ cuyas partes eran el Foro Ecologista de Paraná contra el Gobierno de la provincia de Entre Ríos respecto a los límites de fumigaciones en zonas de escuelas rurales.

Previamente el Foro había presentado una acción de amparo frente a las consecuencias negativas de las fumigaciones sobre las escuelas rurales.

Luego la Cámara Segunda Civil y Comercial dispuso una valiosa respuesta al establecer un límite de protección de 1000 metros para fumigaciones terrestres y 3000 metros para fumigaciones aéreas en zonas lindantes a escuelas rurales. Mediante esta prohibición se exhortaba al Estado provincial para que realizara estudios que determinaran pautas para un uso racional de 
los agroquímicos. También se le requería una evaluación de la contaminación para identificar medidas a adoptarse. Finalmente, condenaba al Estado Provincial y al Consejo General de Educación para que implementaran, en el plazo de dos años, barreras vegetales a una distancia de 150 metros de las escuelas rurales de la provincia y suspendía, de inmediato, la aplicación de agroquímicos en campos aledaños a escuelas rurales en horario de clases (solamente se podía fumigar en horarios de contra turno y/o fines de semana).

Ante este pronunciamiento, el Consejo General de Educación y el Superior Gobierno de Entre Ríos apelo ante el Superior Tribunal de Justicia. El Consejo argumentaba que la sentencia afectaba el principio de congruencia por suspender fumigaciones en horario de clases ya que ello no integraba la pretensión de la parte actora y que como Consejo no tenían competencia sobre este tema.

Mientras que la Fiscalía de Estado de la Provincia fundamentó la apelación en el peligro que esta sentencia ocasionaría al sistema productivo entrerriano y tildando de arbitraria esta disposición judicial y que además se había generalizado sobre el peligro de toxicidad del efecto de las derivas. También la Fiscalía entendía que no existían pruebas acerca del daño al ambiente y la salud para tomar esta medida de urgencia en base al principio precautorio.

Cabe analizar los argumentos de la parte demanda para notar su falta de veracidad. En primer lugar, resulta contradictorio el posicionamiento del Consejo General de Educación que se esgrime en un limitante de competencia, pero opina respecto a una falta de congruencia al suspender fumigaciones sobre escuelas rurales cuando su verdadero rol tendría que consistir en velar por el interés superior de los niños y de los docentes que asisten a estas escuelas. La estructura estatal es coherente con la postura del agronegocio imperante sin importarles los daños que estos insumos químicos generan. En segundo lugar, se aprecia una irresponsabilidad de la Fiscalía de Estado al minimizar los efectos que resultan de las derivas que fueron expuestos en el capítulo anterior. La misma Fiscalía con este criterio había planteado que existía un daño individual cuando 
claramente el daño ambiental afecta de manera integral los recursos naturales como cuencas de agua ampliando el daño de una forma colectiva.

La parte actora había presentado la prueba correspondiente, en el amparo, donde se solicitaba la franja de 1000 metros libres de agroquímicos y 3000 metros en fumigaciones aéreas. También se requería un sistema de vigilancia epidemiológica sobre los niños, niñas y adolescentes como personal docente y no docente a través de análisis de sangre, orina y genéticos de los menores. Por último, se pedía análisis sobre el agua de lluvia y agua utilizada para el consumo de los alumnos ante el riesgo que implicaba sobre el ambiente y la salud de los menores.

Tras este camino judicial la STJ de Entre Ríos planteó la necesidad de tener una visión crítica en estos derechos a un ambiente sano y equilibrado. Destacaron el decreto reglamentario 279 que establece una prohibición de fumigaciones aéreas en el radio de $3 \mathrm{~km}$. sobre la planta urbana.

En aquel entonces no se contaba con una normativa que regulara la utilización de agroquímicos en zonas linderas a escuelas rurales. El STJ destacó que existía una protección para los galpones avícolas ante fumigaciones mientras que los niños y docentes de establecimientos educativos rurales carecían de una protección ante estas situaciones. Por lo tanto, el fallo resultó ejemplificador y buscó suplir esta laguna legislativa y brindar una protección sobre un bien jurídico resonante como es la salud de los niños y docentes de estos establecimientos.

Mediante esta sentencia se instó al Poder Legislativo provincial para que reglamentase esta actividad en zonas de escuelas rurales. El STJ reconoció la trascendencia de esta problemática y la necesidad de un rol activo en esta materia de incidencia colectiva. También se expresó que el ambiente es un bien que forma parte de la sociedad ${ }^{10}$.

10 Esta noción sobre el ambiente fue abordada por la CSJN, en el año 2008, en la causa "Mendoza, Beatriz Silvia y otros c/ Estado Nacional y otros s/ daños y perjuicios". 
Se resaltó que la acción de amparo era la vía idónea para el reclamo de cese de una actividad que genera un daño ambiental como lo profesa el art.30 de la ley 25675. También la Constitución de la provincia de Entre Ríos, en su art.56, recepta el amparo para la protección ambiental ante la existencia de un riesgo con cierto grado de verosimilitud. Y en este sentido quedó acreditado la peligrosidad de las fumigaciones para la salud en consonancia con el principio precautorio normado en la ley 25675 ya que no se pudo probar la inocuidad de estos productos químicos para la salud humana.

También, la STJ expresó que el bien ambiental es limitado cuyo consumo puede resultar irreparable que ocasiona una disminución de la calidad de los seres humanos. Por otro lado, el tribunal no hizo lugar al reclamo de suspender de inmediato la aplicación de agroquímicos ateniéndose al principio de congruencia y cuya protección del bien jurídico de la salud ya se encontraba protegido con los límites de fumigaciones.

2) "FORO ECOLOGISTA DE PARANÁ (2), Y OTRO C/SUPERIOR GOBIERNO DE LA PROVINCIA DE ENTRE RÍOS S/ACCIÓN DE AMPARO" (Causa No 24024)

En mayo de 2019, el Superior Tribunal de Justicia de Entre Ríos (STJER) se expidió nuevamente sobre los límites a fumigaciones

Este caso tuvo su origen en una acción de nulidad solicitada por la ONG Foro Ecologista de Paraná (FEP) y la Asociación Gremial del Magisterio de Entre Ríos (AGMER) frente al decreto provincial $n^{\circ} 4407 / 18$ que fijaba escasas distancias de fumigaciones respecto a escuelas rurales. La parte actora había planteado una medida cautelar con el fin de suspender los efectos del decreto. La normativa violaba las exigencias a la provincia y las distancias para fumigaciones sentadas en el caso "Foro Ecologista 1".

Los actores sostuvieron que el decreto era nulo y el Estado Provincial no contaba con estudios objetivos, de rigor científico, para determinar medidas de protección frente a la exposición de 
agroquímicos. Quedó en evidencia la falta de mesura y responsabilidad del gobierno provincial ya que justificó esta normativa con recomendaciones interministeriales donde se reconocía la toxicidad y daño de los agroquímicos sobre la salud.

Mediante este decreto provincial, el Poder Ejecutivo actuó de manera regresiva ante el requerimiento judicial. Cabe destacar que el Ministerio de Salud de la Provincia y la Secretaría de Ambiente, en consonancia con el gobernador Gustavo Bordet, consideraron idóneas las distancias de fumigación.

Finalmente, en segunda instancia se determinó la nulidad del decreto. Por esta razón el gobierno provincial recurrió ante la STJ argumentando la errónea interposición del amparo por parte de los actores.

El máximo tribunal entrerriano desestimó este planteo y expuso que los derechos de los niños gozan de una protección especial por convenciones internacionales y leyes nacionales. Dicho marco legal exige a los Estados garantizar el interés superior del niño y ante la omisión estatal habilitar vías expeditas y eficaces como la acción del amparo.

Respecto a la acción de amparo ambiental, interpuesta por la parte actora, se asienta en el art.62 de la Ley de Procedimientos Constitucionales $n^{\circ} 8369$ que, ante la restricción, alteración o amenaza de intereses colectivos esta es la vía para reclamar la preservación, protección y conservación del ambiente. Esta norma garantiza la tutela de la salud pública.

Además, se destacó que la sentencia de "Foro Ecologista 1" había pasado por autoridad de cosa juzgada, donde se determinaba la prohibición de fumigación a 1000 metros y 3000 metros a escuelas rurales hasta que se establecieran medidas preventivas por el Estado Provincial. A pesar de esto, se debía revisar la legalidad de este decreto que tuvo su origen en la exigencia de cumplimiento por el fallo precedente. De esta manera, se entendió que el fallo "Foro Ecologista 1" tenía aplicación sobre este nuevo caso estableciendo un piso de derechos que obligaba al Estado a garantizar la salud. 
Mediante el decreto $\mathrm{n}^{\circ} 4407 / 18$ no se pudo acreditar la inocuidad al aplicar agroquímicos entre las distancias de 100 metros y 500 metros alrededor de escuelas rurales. También se ignoró la barrera vegetal de 150 metros que había solicitado el STJER.

Finalmente, el STJER dispuso la nulidad de los artículos 1 y 2 del decreto 4407/18 dejando firme las distancias de 1000 metros para fumigaciones terrestres y 3000 metros para fumigaciones aéreas en zonas aledañas a escuelas rurales.

3) "FORO ECOLOGISTA DE PARANA Y OTRO C/ SUPERIOR GOBIERNO DE LA PROVINCIA DE ENTRE RIOS S/ ACCION DE AMPARO” (Causa N $N^{\circ}$ 9850)

El 26/09/2019 la STJER volvió a ser consultado, en este caso, por la legalidad del decreto 2239/19. La parte actora manifestaba que el decreto vulneraba la cosa juzgada sobre los límites a las fumigaciones y era una normativa de carácter regresivo para la protección a la salud y al ambiente. Solicitaban que se realizaran análisis sobre el agua de lluvia y la utilizada para consumo por los niños ya que casi la totalidad de escuelas rurales no poseen agua potable y sus napas se encuentran expuestas a las fumigaciones. También solicitaban una línea de 1000 metros libres de agroquímicos y que se tomara como referencia la prohibición de las fumigaciones aéreas a 3000 metros del ejido urbano (Decreto 279, 2003, art.12) para aplicarlo en las escuelas rurales.

Se vuelve a reconocer la viabilidad de la acción de amparo interpuesta por la parte actora ya que ante una duda razonable sobre la peligrosidad de una actividad que atañe a la población se deberá admitir la petición del cese de actividad de acuerdo con el principio precautorio de la Ley General del Ambiente.

Respecto a la prueba se entendió que se había incumplido con lo dictado en "Foro 1" ya que no se tomaron medidas para prevenir los efectos nocivos de las fumigaciones sobre la salud de los niños y docentes. Los informes dieron cuenta de la peligrosidad de esta actividad agrícola y que las escasas distancias para fumigarse resultaban insuficientes y vulneraban los Derechos Humanos amparados por los fallos precedentes. 
Finalmente, el STJER resolvió la nulidad por inconstitucionalidad e ilegalidad de los arts. 2, 3 y 4 del decreto 2239/19 y de las normas que en el mismo impliquen reglamentación o aplicación de estos artículos.

4) "FORO ECOLOGISTA DE PARANA (3) Y OTRO C/ SUPERIOR GOBIERNO DE LA PROVINCIA DE ENTRE RIOS S/ ACCION DE AMPARO" (Causa N ${ }^{\circ}$ 24321)

Tras las resoluciones en las causas "Foro 1" y "Foro 2", el 28/10/2019 se presentó un cambio de postura por parte del STJER.

En este caso se realizó un resumen desde la causa madre de "Foro 1" con todo el recorrido judicial que conllevó. Recordando que la Sala $N^{o} 1$ de este máximo tribunal provincial en la causa "Foro 2" había ratificado la cosa juzgada en "Foro 1" sobre las distancias establecidas para fumigarse.

Se entendió que el efecto de cosa jugada de "Foro 1" carecía de efecto expansivo a otras causas ya que contenía disposiciones de carácter transitorio como la prohibición de fumigaciones hasta que se determinara otras medidas preventivas. Sobre estas disposiciones el gobierno provincial, en el plazo de 2 años, promulgó el decreto $n^{\circ} 4407 / 18$ para regular estas fumigaciones siendo el mismo impugnado en "Foro 2".

Según el criterio de la STJER el caso "Foro 1" ya no poseía la naturaleza de cosa juzgada comprendida en la ley general de ambiente (Ley 25675, 2002, art.33) ante las pruebas de daño ambiental emitidas por organismos públicos.

El Superior Tribunal planteó que faltan reglas procesales en material ambiental para la ejecución de las sentencias y otros actos procesales. Por la magnitud y la trascendencia de la materia ambiental, involucrando derechos colectivos que atañen a toda la sociedad, resulta necesario considerar formas de ejecutar las sentencias de manera eficiente, como sugiere la STJER, para evitar continuar con contiendas judiciales inacabables.

También habían quedado firme las barreras vegetales de 150 metros establecidas en "Foro 1" tras un rechazo a un recurso 
extraordinario federal presentado por el Estado Provincial, circunstancia que no fue considerada en el art.2 del decreto $\mathrm{n}^{\circ} 2239 / 19$ ya que esta normativa disponía una distancia de 100 y 500 metros para determinar la zona de exclusión.

Consideraron que el decreto $n^{\circ} 2239 / 19$ había contemplado recomendaciones y estudios sobre las consecuencias de las fumigaciones con medidas que regulaban la aplicación de los agroquímicos.

Algunas de estas medidas fueron la presencia de un ingeniero agrónomo para aplicar los químicos en contra turno, fines de semana y feriados, establecer alarmas pulverizadoras, disponer de un programa de salud para agricultores y habitantes rurales y en particular con un Registro Provincial de Tumores. También se contaba con unidades centinelas conformadas por profesionales y funcionarios especializados y un control on line de información geo referencial para verificar la trazabilidad de los productos.

En este punto la nueva normativa ampliaba el control sobre las fumigaciones, pero las distancias eran sumamente escasas sobre las escuelas rurales dejando latente la afectación a la salud del alumnado y cuerpo docente.

Otro aspecto para destacar son las concepciones que manifestó el STJER sobre los principios ambientales y el decreto. Al analizar los principios de la ley general del ambiente expresan que este decreto es adecuado sobre el principio de sustentabilidad para garantizar el desarrollo económico sin afectar generaciones futuras cuando la agricultura industrial impacta negativamente sobre el ambiente por la toxicidad de estos químicos. Un modelo acorde al principio de sustentabilidad es la agroecología que produce los mismos alimentos que la agricultura industrial sin afectar al ambiente ni a la salud de las personas.

Tampoco se cumple con el principio de progresividad porque el decreto reduce la distancia mínima para fumigar de 150 metros a 100 metros. Este principio debe contemplar limites a 
derechos individuales de una manera gradual para proteger el ambiente (Esain, 2007, pág.11-23) cuando este poder de policía se redujo en 50 metros.

También se analiza de manera errónea el principio de congruencia ya que el decreto 4407/19 es contrario al art.22 de la Constitución de la Provincia de Entre Ríos que garantiza un ambiente sano. Por ende, el principio de congruencia plantea que las provincias deben adecuarse a lo dispuesto por la Ley General del Ambiente y pueden complementar, legislativamente, esta protección ambiental (Villafañe, 2017, pág.154).

Finalmente, la STJER rechazó parcialmente la apelación por el Estado provincial sobre la nulidad del art.2 del Decreto $\mathrm{n}^{\circ} 2239 / 19$ solamente relacionado a la distancia de la zona de exclusión que deberá ser medida a partir de una barrera vegetal. Revocó el pronunciamiento en revisión rechazando el amparo del Foro dejando en vigencia el decreto. Y condenó al Estado Provincial para que subsanara el art. 2 del decreto mientras que exhortó al poder legislativo provincial para que dicte una ley sobre la aplicación de agroquímicos.

5) "FORO ECOLOGISTA DE PARANA (3) Y OTRO C/ SUPERIOR GOBIERNO DE LA PROVINCIA DE ENTRE RIOS S/ ACCION DE AMPARO"(Causa N 24321)

Tras la resolución dictada por el Superior Tribunal, las accionantes interpusieron un recurso extraordinario federal en miras de llevar el caso a la Corte Suprema de Justicia de la Nación. Las actoras fundaron la viabilidad del recurso ya que se deducía contra una sentencia definitiva y la cuestión federal había sido planteada desde inicio del proceso. Plantearon la arbitrariedad del pronunciamiento al omitir prueba decisiva para el proceso vulnerando el principio de cosa juzgada y el de no regresión convalidando una medida que afectaba la salud de niños y docentes.

Es oportuno destacar que de acuerdo con el art. 257 del Código Procesal Civil y Comercial de la Nación, el tribunal de la causa es el competente para dirimir la admisibilidad o no 
de este recurso extraordinario mediante la verificación de los requisitos necesarios para su interposición.

El día 7 de febrero de 2020 la STJER, con sus miembros, rechazó el recurso extraordinario federal interpuesto por el Foro Ecologista porque carecía del requisito de sostener la cuestión federal durante todo el proceso judicial más allá que las actoras lo hayan planteado en la etapa inicial del proceso a través de la demanda. También expuso que el presente recurso no comprende el tratamiento de hechos y pruebas como habían ponderado las actoras y que la fundamentación de la sentencia recurrida era acorde a normas de derecho público local.

\section{Conclusiones}

A través de este trabajo se ha abordado las consecuencias de los agroquímicos en la provincia de Entre Ríos mediante las distintas normativas que tuvieron como objetivo regular esta problemática. Se analizó la evolución jurisprudencial sobre los casos de "Foro Ecologista" entre avances y retrocesos.

En este final es interesante hablar sobre algunas cuestiones tratadas en los párrafos precedentes como la dificultad que se presenta en la ejecución de sentencias ambientales.

A través de una sentencia se materializa la respuesta de los jueces hacia el derecho que los ciudadanos reclaman para garantizar el acceso a la justicia de todas las personas (Catalano, 2017, pág.75).

En el caso de los procesos colectivos, por sus particularidades, precisan de elementos efectivos que permitan la ejecución de las sentencias. Para evitar que un derecho quede en expectativa en la materia ambiental, el juez puede disponer de medidas cautelares de oficio para proteger el interés general y en las sentencias, en base a la sana crítica, podrá extender el fallo a cuestiones no sometidas expresamente por las partes (Ley 25675, 2002, art.32).

Al momento de dirimir estos problemas socioambientales que afectan al ambiente y a las personas que lo habitan es 
dable entender al ambiente como la casa común de todos los seres humanos. En la encíclica "Laudato si'" el Papa Francisco recae sobre la necesidad de un cambio de paradigma en el vínculo entre los individuos y el ambiente, es decir, pasar del mero explotador y consumidor de los bienes de la naturaleza a una sociedad que se preocupe por toda la familia humana en la búsqueda de un desarrollo sostenible e integral. En este camino se enfrentan con el rechazo de los poderosos y la indiferencia de otros.

Mediante una cultura de descarte sobre aquellas personas que son ignoradas por el sistema político y económico se genera una desigualdad social. Las últimas decisiones judiciales que se trataron en Entre Ríos como el accionar del gobernador Bordet exhiben un posicionamiento en favor del agronegocio. De esta manera ignoran un reclamo latente y fundado sobre los peligros que conllevan las fumigaciones en la salud de niños y docentes.

Nos encontramos como testigos frente una degradación ambiental que enferma a los pueblos fumigados que viven cotidianamente con esta situación. Estas graves inequidades entre los intereses del modelo de agricultura industrial sobre este colectivo afectado nos dejan un costo a todos como humanidad.

Por esta razón expresa el Papa Francisco: "Un verdadero planteo ecológico se convierte en un planteo social"11. Entonces es indispensable un poder judicial consciente de la gravedad que se presenta en las fumigaciones con agroquímicos y escuche el clamor de los pueblos excluidos por este sistema de producción intensiva.

Por último, el poder ejecutivo y legislativo deben proponer soluciones integrales ya que los problemas se originan a través de la interacción de los seres humanos con el ambiente que habitan. Por ende, como sociedad la mirada sobre los problemas

11 Papa Francisco (2015), “Carta Encíclica Laudato si” del Santo Padre Francisco sobre el cuidado de la casa común", Roma, pág. 39. 
ambientales debe abarcar las aristas sociales, referidas la relación entre los individuos con la naturaleza, y económicas sobre el tipo de desarrollo que se utiliza para la producción. (Papa Francisco, 2015, pág.22)

\section{Bibliografía}

Boletín Oficial Prov. De Entre Ríos (2019) Decreto $N^{\circ}$ 2239. En línea en: https://www.entrerios.gov.ar/boletin/calendario/ Boletin/2019/Agosto/05-08-19.pdf

Corte Suprema de Justicia de la Nación (2008) "Mendoza, Beatriz Silvia y otros c/ Estado Nacional y otros s/ daños y perjuicios". En línea en:

http://www.saij.gob.ar/corte-suprema-justicia-nacion-federalciudad-autonoma-buenos-aires-mendoza-beatriz-silvia-otrosestado-nacional-otros-danos-perjuicios-danos-derivadoscontaminacion-ambiental-rio-matanza-riachuelo-fa080000472008-07-08/123456789-740-0008-0ots-eupmocsollaf

Iglesia Católica. Papa (2015-: Francisco) Carta Encíclica Laudato si del Santo Padre Francisco sobre el cuidado de la casa común. Roma

INDEC (2017a) Censo Nacional Agropecuario. En línea en: https:// www.indec.gob.ar/indec/web/Institucional-Indec-Multimedia-1

- (2017b) Censo Nacional Agropecuario. En línea en: https://www. indec.gob.ar/indec/web/Institucional-Indec-Multimedia-1

- (2018) Informes Técnicos sobre Comercio Exterior y sobre "Complejos Exportadores". En línea en: https://sitioanterior. indec.gob.ar/uploads/informesdeprensa/complejos_03_19.pdf

- (2020) Informes Técnicos sobre Comercio Exterior. En línea en: https://www.indec.gob.ar/uploads/informesdeprensa/ica_ 01_20B13D104EBD.pdf

Página 12 (2019) "Entre Ríos: insólita defensa de los agrotóxicos" https://www.pagina12.com.ar/195153-entre-rios-insolitadefensa-de-los-agrotoxicos 